\title{
The new means of biomass thermal conversion analysis
}

\author{
L.S. $X U^{1, a} \& R \cdot L I^{1, a *}$ \\ M.H. GU \\ ${ }^{1}$ Department of Forest Chemical Processing Engineering, BeijingForestryUniversity, Beijing \\ 100083,China \\ ${ }^{a *}$ Corresponding Author:boxlr@126.com \\ ${ }^{2}$ Lianyungang WorleyParsons Engineering Co.Ltd, Shanghai 200000,China
}

KEYWORD: Biomass thermal conversion; Thermogravimetry; TGA; Simulation

ABSTRACT: In this paper, thermogravimetric analysis method was studied in biomass thermal conversion analysis. Theoretical simulation and experimental methods indicated the problems existing in the traditional thermogravimetric analyzer (TGA). On this basis, a new thermogravimetric analysis platform was developed. The equipment has high heating rates, and the method of direct contact is used for heating and temperature measurement, which provided a new means for the biomass thermal conversion analysis.

\section{INTRODUCTION}

Biomass can be transformed into renewable energy by thermal conversion technology, such as: bio oil, bio asphalt, bio ethanol and carbon etc(Shaddix,1999; Damartzis,2011). The kinetics of thermal conversion is the key of the research, the main means of studying kinetics is thermogravimetric analysis methods(Zhou,2006). The thermal gravity (TG)/differential thermal gravity(DTG) curves can be determined through TGA(Chao,2013). TGA is widely used to study the phenomenon of biomass thermal degradation, synthesis, dehydration, adsorption and evaporation (Damartzis,2011). And component analysis, thermal parameters and kinetic parameters can be determined(Ninan,1989), which has the advantages of simple operation, quick and convenient (Hatakeyama,1999).

However, the deviations of measured temperatures between temperature measuring points and the internal sample may not be ignored on traditional TGA due to the sample is heated unevenly, which cause errors in temperature measurement system. Meanwhile, traditional TGA requires high accuracy and is easy to be interfered by environment. And the heating rates are limited because that the heating system and temperature measurement are not directly contacted with samples.

This paper mainly used computational fluid dynamics (CFD) to simulate sample internal temperature distribution on traditional TGA. On this basis, our group developed a new thermogravimetric analysis platform, which can make up for the deficiencies of traditional thermogravimetric analysis.

\section{THEORETICAL ANALYSIS OF TRADITIONAL TGA}

Traditional TGA mainly consists of temperature control system, detection system and recording system. The detection system profile is shown in Figure 1. Nitrogen is heated in the furnace at room temperature, the sample in the crucible is heated by the way of radiation and convection. However, the thermocouples at the bottom of the crucible and metal plate, have some differences with the samples in the affect of radiation and gas heat transfer. At the same time, the samples are separated with thermocouple by the crucible, the bottom gap and the metal plate, which cause the thermal resistance between them, so there may be differences in temperature measurement. In this study, internal temperature distribution of the furnace is analyzed by simulation, aiming at studying the difference between the measured temperature and the real one. 


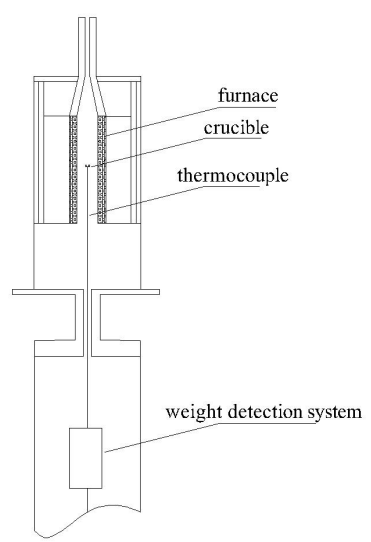

Figure 1. The detection system profile

\section{Numerical calculation equation and boundary conditions}

FLUENT software was used to simulate the furnace, nitrogen gas jet into it from the inlet, which can be regarded as free turbulence. For the whole furnace, using k- $\varepsilon$ turbulence model, SIMPLE algorithm and the second order upstream scheme for simulation. Computational equations are as follows:

Mass conservation equation

$$
\frac{\partial \rho}{\partial t}+\frac{\partial(\rho u)}{\partial x}+\frac{\partial(\rho v)}{\partial y}+\frac{\partial(\rho w)}{\partial z}=0
$$

Momentum conservation equation

$\mathrm{X}$ momentum equation:

$$
\begin{aligned}
& \frac{\partial(\rho u)}{\partial t}+\frac{\partial(\rho u u)}{\partial x}+\frac{\partial(\rho u v)}{\partial y}+\frac{\partial(\rho u w)}{\partial z}= \\
& \frac{\partial}{\partial x}\left(\mu \frac{\partial u}{\partial x}\right)+\frac{\partial}{\partial y}\left(\mu \frac{\partial u}{\partial y}\right)+\frac{\partial}{\partial z}\left(\mu \frac{\partial u}{\partial z}\right)-\frac{\partial p}{\partial x}+S_{u}
\end{aligned}
$$

Y momentum equation:

$$
\begin{aligned}
& \frac{\partial(\rho v)}{\partial t}+\frac{\partial(\rho v u)}{\partial x}+\frac{\partial(\rho v v)}{\partial y}+\frac{\partial(\rho v w)}{\partial z}= \\
& \frac{\partial}{\partial x}\left(\mu \frac{\partial v}{\partial x}\right)+\frac{\partial}{\partial y}\left(\mu \frac{\partial v}{\partial y}\right)+\frac{\partial}{\partial z}\left(\mu \frac{\partial v}{\partial z}\right)-\frac{\partial p}{\partial y}+S_{v}
\end{aligned}
$$

$\mathrm{Z}$ momentum equation:

$\frac{\partial(\rho w)}{\partial t}+\frac{\partial(\rho w u)}{\partial x}+\frac{\partial(\rho w v)}{\partial y}+\frac{\partial(\rho w w)}{\partial z}=$

$\frac{\partial}{\partial x}\left(\mu \frac{\partial w}{\partial x}\right)+\frac{\partial}{\partial y}\left(\mu \frac{\partial w}{\partial y}\right)+\frac{\partial}{\partial z}\left(\mu \frac{\partial w}{\partial z}\right)-\frac{\partial p}{\partial z}+S_{z}$

In the formula (1-4), $\rho$ is density, $t$ is time, $u, v$ and $w$ is the velocity vector, $\mu$ is the kinetic viscosity and $p$ is the pressure element.

Energy conservation equation

$$
\frac{\partial(\rho T)}{\partial t}+\operatorname{div}(\rho u T)=\operatorname{div}\left(\frac{k}{c_{p}} \operatorname{grad} T\right)+S_{T}
$$

This formula can be written in form:

$$
\begin{aligned}
& \frac{\partial\left(\rho c_{s}\right)}{\partial t}+\frac{\partial\left(\rho c_{s} u\right)}{\partial x}+\frac{\partial\left(\rho c_{s} v\right)}{\partial y}+\frac{\partial\left(\rho c_{s} w\right)}{\partial z}= \\
& \frac{\partial}{\partial x}\left(\frac{k}{c_{p}} \frac{\partial T}{\partial x}\right)+\frac{\partial}{\partial y}\left(\frac{k}{c_{p}} \frac{\partial T}{\partial y}\right)+\frac{\partial}{\partial z}\left(\frac{k}{c_{p}} \frac{\partial T}{\partial z}\right)+S_{T}
\end{aligned}
$$


Where $c_{p}$ is specific heat, $T$ is temperature, $k$ is the heat transfer coefficient of fluid and $S_{T}$ is viscous dissipation.

Radiative transfer equation

$\frac{d I\left(\begin{array}{l}1 \\ r, s\end{array}\right)}{d s}+\left(a+\sigma_{s}\right) I(\stackrel{r}{r}, \stackrel{r}{s})=$

$a n^{2} \frac{\sigma T^{4}}{\pi}+\frac{\sigma_{s}}{4 \pi} \int_{0}^{4 \pi} I\left(\begin{array}{r}r \\ r\end{array}, s^{\prime}\right) \phi\left(s \cdot s^{r} \cdot s^{\prime}\right) d \Omega^{\prime}$

Where $' r$ is position vector, $s$ is direction vector, $s^{\prime}$ is scattering direction vector, $s$ is path length, $a_{\text {is absorption coefficient, }} n_{\text {is refractive index, }} \sigma_{s}$ is scattering coefficient, $\sigma$ is StefanBoltzmann constant $\left(5.669 \times 10^{-8} \mathrm{~W} /\left(\mathrm{m}^{2} \cdot \mathrm{K}^{4}\right)\right), I$ is radiation intensity, which depends on $' r$ position and 's direction, $T$ is local temperature, $\phi$ is phase function, $\Omega^{\prime}$ is solid angle, $\left(a+\sigma_{s}\right)$ is the optical thickness or opacity of the medium. The refractive index $n$ is important when considering radiation in semi-transparent media.

The temperature distribution of the furnace was simulated, and the boundary conditions of the flow field were mainly including fluid types, material types, inlet flow rate, etc. Specifically as described in Table 1.

Table 1 Boundary conditions of furnace

\begin{tabular}{ll}
\hline Fluid (material type) & Nitrogen \\
\hline Wall temperature $\left({ }^{\circ} \mathrm{C}\right)$ & 500,800 \\
Internal initial tempera- & 300 \\
ture $\left({ }^{\circ} \mathrm{C}\right)$ & \\
Inlet flow rate $(\mathrm{ml} / \mathrm{min})$ & 50 \\
Inlet diameter $(\mathrm{mm})$ & 12 \\
Inlet velocity $(\mathrm{m} / \mathrm{s})$ & 0.07 \\
Crucible height $(\mathrm{mm})$ & 4 \\
Crucible diameter & 3 \\
(mm) & Dolomite(cao_mgo_2co2) \\
Crucible material & wood \\
Sample type & \\
\hline
\end{tabular}

In the calculation, the partial and the whole grid density are increased respectively to ensure the accuracy of the calculation, as shown in Figure 2.

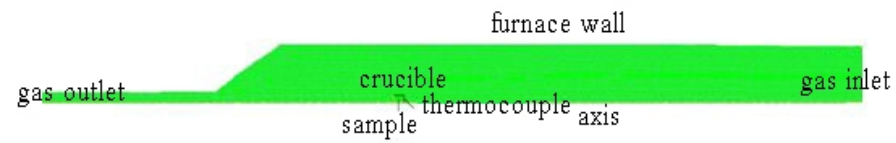

Figure 2. The sketch of grids division and boundary conditions 


\section{Numerical Simulation Results}

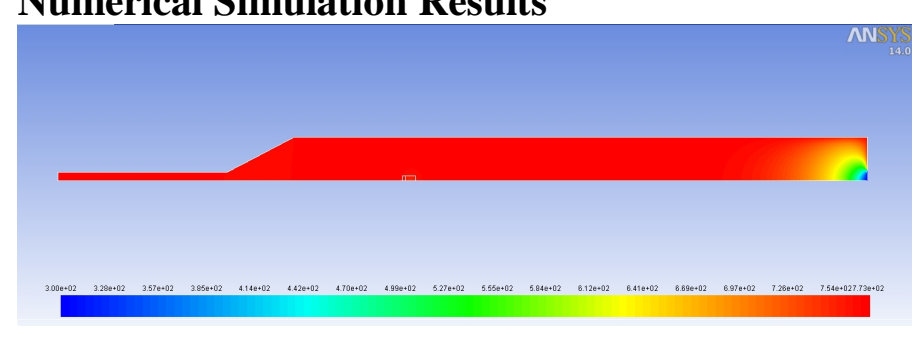

Figure 3. The temperature distribution of furnace

Nitrogen is gradually heated via the inlet into the furnace, temperature gradient distributions can be seen from Figure 3, according to the temperature changes of the samples at different times in simulation process, the heating rate of the simulation process is $120{ }^{\circ} \mathrm{C} / \mathrm{min}$.

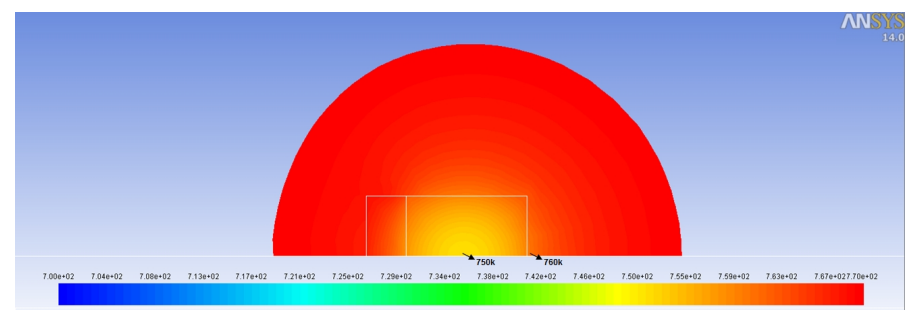

Figure 4. The temperature distribution of crucible region

It can be seen from Figure 4, the sample measured temperature was $10^{\circ} \mathrm{C}$ lower than the internal temperature, which is because that the thermocouple positions in the interior and bottom of the crucible respectively had big differences on radiation and convection heat transfer, meanwhile, thermal conduction resistance and thermal contact resistance were existed between the thermocouple and sample. At this time, the temperature of the sample was $750 \mathrm{k}$, when the sample initial temperature was smaller and the heating rate was lower, the measured temperature deviation would be larger.

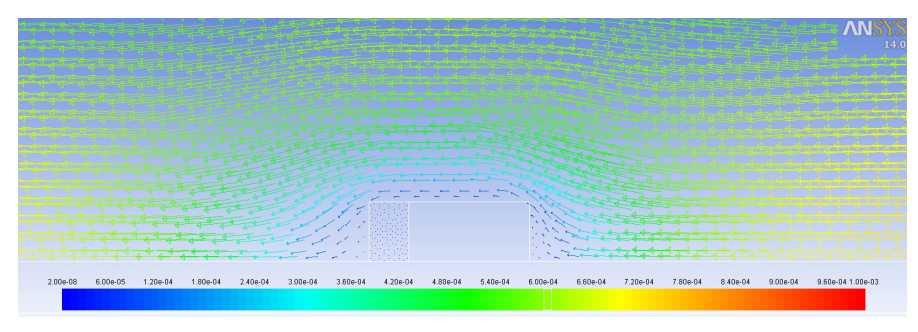

Figure 5. The gas velocity distribution

The velocity distribution of nitrogen flowed through the crucible was shown in Figure 5. In addition to the radiation heat transfer, the inhomogeneity of the gas flowed in the upper and lower reaches of the crucible had an effect on the internal temperature of the sample, which was further caused the temperature deviation.

The higher sensitivity and stability of the measurement system are required on traditional TGA. Moreover, the sample mass ranges are generally in $0-100 \mathrm{mg}$ and individual can reaches $500 \mathrm{mg}$. The temperature gradients in the crucible would be more obvious if sample mass or volume is larger, the real temperature of the sample may not be measured by the surface temperature. Thus, traditional TGA is unable to meet the demand of thermal conversion analysis. 


\section{DEVELOPMENT OF THE NEW THERMOGRAVIMETRIC ANALYSIS PLATFORM}

Based on the theoretical simulation, our team optimized the traditional TGA and developed a new type of thermogravimetric analysis platform, It is consisting of sample heating system, protective gas conveying system, temperature acquisition and automatic control system, weight acquisition system, data processing and control system. The detail information was illustrated in our applying patent and the prototype was showed in Figure 6.

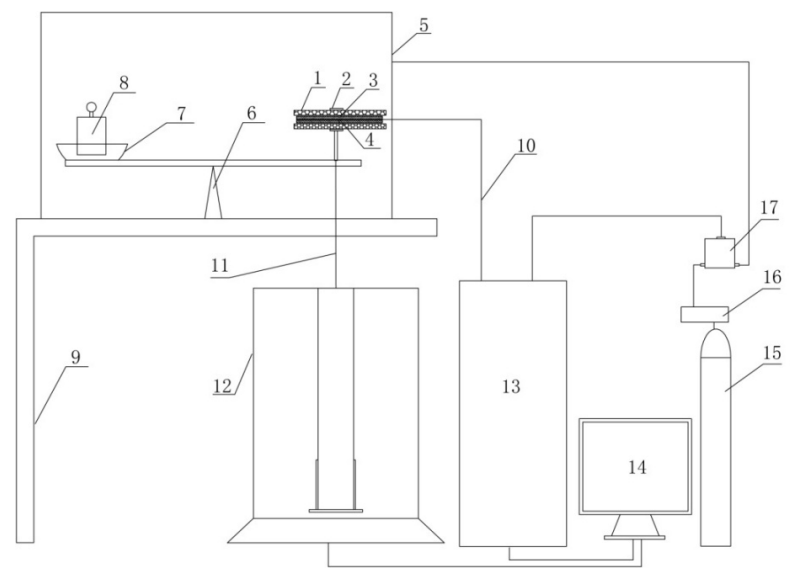

Figure 6. The sketch of the thermogravimetric prototype

*1 Heating plates 2 Clamping device

3 External thermocouple

4 Internal thermocouple 5 seal cover

6 Weight transfer device 7 Tray

8 Balancing weight 9 Holder

10 Temperature sensor 11 Connecting device

12 Electronic scale

13 PLC intelligent control device

14 Computer 15 Nitrogen cylinder

16 Reducing valve 17 Mass flowmeter

The experiments used two samples, which were overlapped with each other and sandwiched between two heating elements. The temperature sensor used $0.5 \mathrm{~mm}$ diameter $\mathrm{NiCr}-\mathrm{NiAl}$ thermocouple wire, detecting temperatures ranged from $0^{\circ} \mathrm{C}$ to $1300^{\circ} \mathrm{C}$ with the accuracy of $0.1^{\circ} \mathrm{C}$. The external thermocouple was set between the heating element and the sample to measure the outside temperature. The internal thermocouple was placed between the two samples to measure their inside temperature. The electronic scale collected the data of the samples and transferred them to computer through lever weight transfer device, steel wires and connecting device.

The data processing and controlling system consisted of the VB software, visualized configuration software KingView and PLC intelligent control system. The thermogravimetric curves can be obtained by collecting and analyzing the data. The lever weight transfer device simplified the weight collecting system, got more accurate data, overcame the experiment limits of traditional thermal weight analysis, diminished the deviation between the measured and real temperature, which met the requirements of the thermal conversion analysis to a higher degree.

\section{EXPERIMENT}

\section{Experimental material}

Eucalyptus was selected for the thermogravimetric experiments in present study. The raw materials were obtained from Guangxi Province, China. The samples were air-dried and sliced into sheets with 
a surface area of $50 \mathrm{mmÕ} 10 \mathrm{~mm}$ and thickness of $2 \mathrm{~mm}$ for the test on new thermogravimetric analysis platform, and respectively used wood powder under sieve mesh 80 , wood block of $2 \mathrm{~mm}^{3}$ size on traditional TGA. The composition analysis of the eucalyptus are shown in Table 2.

Table 2

Characteristics of eucalyptus (\%)

\begin{tabular}{c|c}
\hline Sample & Eucalyptus \\
\hline Cellulose & 41.02 \\
Hemicellulose & 20.21 \\
Lignin & 30.43 \\
Moisture & 5.8 \\
ash & 0.3 \\
\hline
\end{tabular}

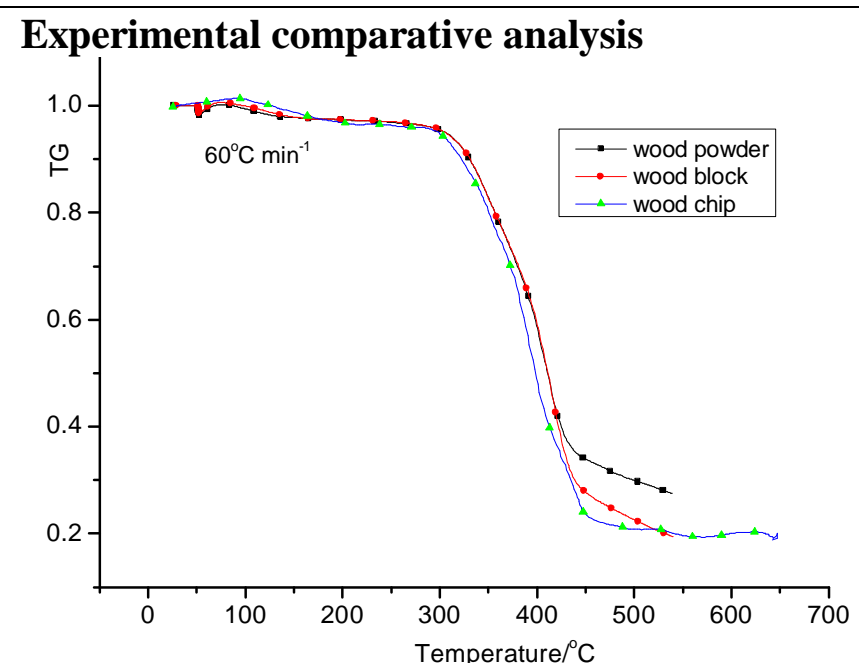

Figure 7. The TG curves at the heating rate of $60{ }^{\circ} \mathrm{C} / \mathrm{min}$ on the two TGAs

The heating rate was controlled at $60^{\circ} \mathrm{C} / \mathrm{min}$ and three samples were tested in this experiment. According to the theoretical analysis, the heat transfer rate of the samples was significantly higher than the heating rate. From the Figure 7 we can see that the TG curve on the new thermogravimetric analysis platform was below the traditional ones and the tendency was in consistent. But above the temperature of $500^{\circ} \mathrm{C}$, traditional TGA had a large interference by air flow and other factors at the end of the measurement, and repeatability of the residual weight is not good.

The new thermogravimetric analysis platform can measure the sample's temperature and weight more accurately, and it can make up the deficiency of the traditional thermogravimetric analysis method by direct contact on heating and temperature measurement. High heating rates are more conformed to the requirement of biomass thermal conversion. So our team had done further research about biomass pyrolysis kinetics using the new thermogravimetric analysis platform. 


\section{Experimental results on the new thermogravimetric analysis platform}

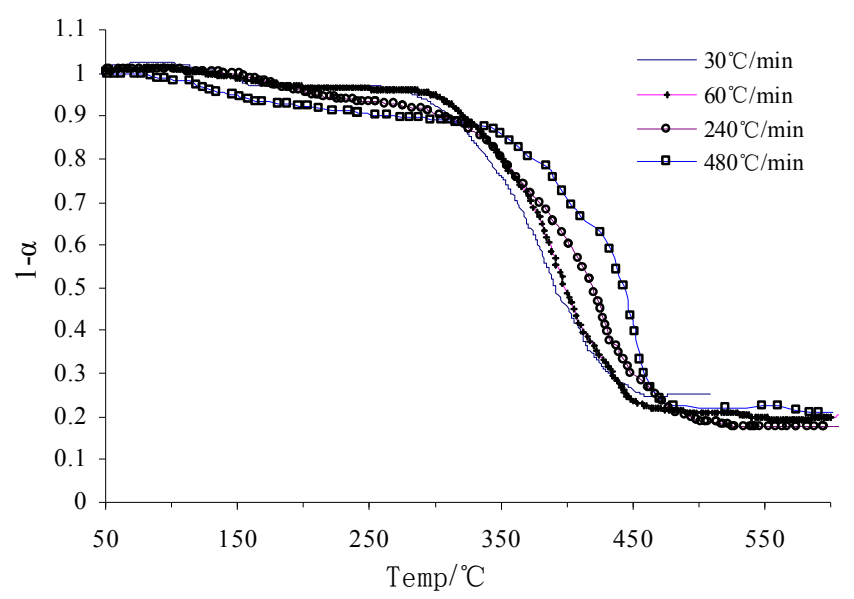

Figure 8. The TG curves for the samples under different heating rates

In a typically run, the samples were fixed horizontally between two pieces of heating plates and heated from room temperature to $600^{\circ} \mathrm{C}$ in nitrogen condition at programmed heating rates of $30^{\circ} \mathrm{C}$ $\min ^{-1}, 60^{\circ} \mathrm{C} \min ^{-1}, 240^{\circ} \mathrm{C} \min ^{-1}$ and $480^{\circ} \mathrm{C} \mathrm{min}^{-1}$ respectively. Continuous measurement of the mass loss of the sample was done by an electronic scale. The temperature and the mass of the sample were recorded every second in computer software. Each rate was repeated several times to reduce any possible error. As shown in Figure 8, the TG curves were obtained. On this basis, further study can be carried to acquire the kinetic parameters and reveal the pyrolysis mechanism.

\section{CONCLUSIONS}

Thermogravimetry is an important analysis method of biomass thermal conversion, which can intuitively describe the changes of the materials in the process of biomass transformation. By this method, we can characterize structural changes, analyze residues and research kinetic parameters etc.

The traditional TGA has the problems that the high requirement of measurement accuracy, little samples, deviation of temperature measurement and the low heating rates, which had been analyzed through the theoretical simulation and experimental analysis.

The new thermogravimetric analysis platform optimized the traditional one on the basis of the theoretical simulation. The new equipment has high heating rates and the method of direct contact is used for heating and temperature measurement, the sample size is larger and the repeatability is good. The experiments demonstrated that the data from the new thermogravimetric analysis platform can consistent with the traditional TGA well at the low heating rates. Thus we can do the further study on thermal conversion by the new means.

\section{ACKNOWLEDGEMENTS}

The authors would like to acknowledge the support of "the efficient utilization of sapindus biodiesel and saponin" cooperated with SanQing Ecological Agriculture and Forestry Development Co.Ltd in Fujian.

\section{REFERENCES}

[1] Damartzis, T. \& Vamvuka, D. 2011. Thermal degradation studies and kinetic modeling of cardoon (Cynara cardunculus) pyrolysis using thermogravimetric analysis (TGA). Bioresoure Technology 102:6230-6238.

[2] Dridgwater, A.V. 2003. Renewable fuels and chemicals by thermal processing of biomass [J]. Chemical Engineering Journal 91(2):87-102. 
[3] Hatakeyama, T. \& Quinn, F.X. 1999. Thermal Analysis-Fundamentals and Applications to Polymer Science, Wiley, Chichester

[4] Kirubakaran, V, Sivaramakrishnan, V, \& Nalini, R. 2009. A review on gasification of biomass [J]. Renewable and Sustainable Energy Reviews 13(1):179-186.

[5] Ninan, K.N. 1989. Kinetics of solid-state thermal decomposition reactions [J]. Journal of Thermal Analysis 35: 1267-1278.

[6] Shaddix ,C.R. \& Hardesty, D.R. 1999. Combustion properties of biomass flash pyrolysis oils. Final Report, Combustion Research Facility, Sandia National Laboratories, Livermore, CA.

[7] Zhou, L.M., Wang, Y.P., Huang, Q.W. \& Cai, J.Q. 2006. Thermogravimetric characteristics and kinetic of plastic and biomass blends co-pyrolysis. Fuel Processing Technology 87: 963-969. 